Conflict of Interest: The authors of this paper have no conflicts of interest, including specific financial interests, relationships, and/or affiliations relevant to the subject matter or materials included.

\section{References}

1. Kypson AP, Rodriguez E, Anderson CA. Coronary surgery in a hemophiliac with continuous factor VIII replacement. Asian Cardiovasc Thorac Ann 2012;20:191-192.
2. Shalabi A, Spiegelstein D, Lipey A, Kassif Y, Misgav M, Kogan A, Raanani E. Cardiac surgery in patients with hemophilia A and B. In: 62nd Annual Conference of the Israel Heart Society; Tel Aviv, Israel; 13-14 April 2015.

3. Srivastava A, Brewer AK, Mauser-Bunschoten EP, Key NS, Kitchen S, Llinas A, Ludlam CA, Mahlangu JN, Mulder K, Poon MC, Street A; Treatment Guidelines Working Group on Behalf of the World Federation of Hemophilia. Guidelines for the management of hemophilia. Haemophilia 2013;19:1-47.

\title{
Prospective Evaluation of Non-Compliant Severe Hemophilia Patients
}

Tedaviye Uyumsuz Ağır Hemofili Hastalarının Prospektif Değerlendirilmesi

(D) Mehmet Can Uğur1, (D) Kaan Kavaklı2

1 University of Health Sciences, Izmir Bozyaka Training and Research Hospital, Clinic of Hematology, Izmir, Turkey

${ }^{2}$ Ege University Faculty of Medicine, Department of Pediatric Hematology, Izmir, Turkey

To the Editor,

Patient compliance with the determined treatment regimen is a current issue in the treatment of hemophilia, and there are many studies that report compliance issues in patients with hemophilia $[1,2]$.

In our study, we applied a survey to 40 patients who participated in the adolescent workshop of Hemophilia Federation in March 2017, and we monitored 16 adolescent patients with severe hemophilia and investigated the changes in their compliance rates during a 1-year period. The survey was applied using face-to-face method. Subjects who were found to be non-compliant (patients who neglect to apply prophylaxis as recommended by their physicians) were monitored for 1 year. These subjects were reached by phone in months 6 and 12. The scope of these telephone calls was as follows: whether the subject was currently on prophylaxis, whether they were complying with the treatment plan, and the reasons for non-compliance.

This survey was an activity initiated for patients during a routine workshop. Therefore, we did not apply for ethics committee approval.
There were a total of 40 subjects: thirty nine patients with severe hemophilia and 1 patient with von Willebrand disease (vWD). Among these subjects, 16 were found to be noncompliant: twelve patients with hemophilia $A, 3$ patients with hemophilia $B$, and 1 patient with vWD. The average age of these 16 subjects was 21.25 years. Ten patients $(62.5 \%)$ were receiving prophylaxis. Two of the patients were middle school, 11 were high school, and 3 were university graduates.

There were 10 patients who were receiving prophylaxis at the start of study. The number of patients on prophylaxis increased to 12 and 14 at 6 and 12 months of follow-up. The rate of compliant patients was $43.75 \%$ in the sixth month and $56.25 \%$ in the first year.

It was determined that there were three reasons for noncompliance with the treatment: time constraints, being tired of the treatment, and problems with vascular access. The number of patients reporting these problems is presented in Table 1 .

The definition of "acceptable compliance" can greatly different between studies. Generally, if patients administer at least 75\% to $80 \%$ of the recommended doses, they are accepted to have perfect compliance [3]. Sixteen subjects who were found to be 


\begin{tabular}{|c|c|c|c|}
\hline & $\begin{array}{l}\text { Time } \\
\text { constraints } \\
\text { (n) }\end{array}$ & $\begin{array}{l}\text { Being tired of } \\
\text { the treatment } \\
\text { (n) }\end{array}$ & $\begin{array}{l}\text { Problems with } \\
\text { vascular access } \\
\text { (n) }\end{array}$ \\
\hline Month 0 & 3 & 7 & 6 \\
\hline Month 6 & 3 & 4 & 2 \\
\hline Month 12 & 3 & 4 & 0 \\
\hline
\end{tabular}

non-compliant were monitored for 1 year, and it was determined that the rate of compliance increased only to $56.25 \%$ in our prospective cohort study.

Adolescent patients are more resistant to comply with recommended treatment plans. In this age group, the patients go through several biological, social, and emotional changes that influence their approach to the disorder [4]. Due to these factors, the non-compliance problem has a complicated nature that cannot be resolved through advising only. Treatment nonadherence is a chronic process in life-long chronic diseases such as hemophilia. As each patient is affected by different factors, it might be useful to conduct individual meetings with each patient instead of group trainings.

Keywords: Hemophilia, Compliance, Adolescent

Anahtar Sözcükler: Hemofili, Tedavi uyumu, Adölesan

Conflict of Interest: The authors of this paper have no conflicts of interest, including specific financial interests, relationships, and/or affiliations relevant to the subject matter or materials included.

\section{References}

1. van Os SB, Troop NA, Sullivan KR, Hart DP. Adherence to prophylaxis in adolescents and young adults with severe haemophilia: a quantitative study with patients. PLoS One 2017;12:e0169880.

2. Khair K. Compliance, concordance and adherence: what are we talking about? Haemophilia 2014;20:601-603.

3. Thornburg CD. Physicians' perceptions of adherence to prophylactic clotting factor infusions. Haemophilia 2008;14:25-29.

4. Brand B, Dunn S, Kulkarni R. Challenges in the management of haemophilia on transition from adolescence to adulthood. Eur J Haematol 2015;95(Suppl 81):30-35.

\section{Bleomycin-Induced Flagellate Dermatitis}

\section{Bleomisin ile Illişkili Flagella Dermatit}

(1) Esra Turan Erkek ${ }^{1}$, (1) Ceren Nur Karaali2 , (1) Güven Yılmaz ${ }^{1}$, (1) Emine Gültürk1

${ }^{1}$ Lütfi Kırdar Training and Research Hospital, Clinic of Hematology, Istanbul, Turkey

${ }^{2}$ Bahçeşehir University Faculty of Medicine, Istanbul, Turkey

To the Editor,

Bleomycin is a cytostatic, antineoplastic antibiotic that is used in both of the first-line treatments of Hodgkin lymphoma: ABVD (doxorubicin, bleomycin, vinblastine, dacarbazine) and BEACOPP (doxorubicin, bleomycin, vincristine, cyclophosphamide, etoposide, prednisone, procarbazine). The bleomycin hydrolase enzyme metabolizes bleomycin. This enzyme is not found in the skin or lung tissues; therefore, bleomycin accumulates in those areas and causes side effects [1]. The dermatologic side effects of bleomycin may vary from onycholysis, pruritus, and scleroderma-like skin changes to Stevens-Johnson syndrome. Flagellate dermatitis, resulting after bleomycin therapy, was originally described by Moulin et al. [2] in 1970 as "bleomycin-induced linear hyperpigmentation" [3]. Although the term "flagellate dermatitis" was described for bleomycin-induced dermatitis, other causes of this symptom have been defined over time (Table 1) [4]. The characteristic symptoms are pruritic linear hyperpigmentations, arranged in a flagellate pattern and developing, in particular, on the trunk. Even though the exact mechanism is not clear, minor skin traumas are thought to be responsible since they increase blood flow to the affected area and cause drug accumulation [1].

We present a 24-year-old female patient who was diagnosed in August 2016 with stage IIA Hodgkin lymphoma (right cervical, submandibular, and bilateral palatine tonsil involvement 